\title{
Versican V0 and V1 Direct the Growth of Peripheral Axons in the Developing Chick Hindlimb
}

\author{
Shilpee Dutt, ${ }^{1}$ Estelle Cassoly, ${ }^{1}$ María T. Dours-Zimmermann, ${ }^{1}$ Mattia Matasci, ${ }^{1}$ Esther T. Stoeckli, ${ }^{2 \star}$ \\ and Dieter R. Zimmermann ${ }^{1 *}$ \\ ${ }^{1}$ Institute of Surgical Pathology, University Hospital Zurich, CH-8091 Zurich, Switzerland, and ${ }^{2}$ Institute of Molecular Life Sciences, University of Zurich, \\ CH-8057 Zurich, Switzerland
}

Peanut agglutinin-binding disaccharides and chondroitin sulfate mark transient mesenchymal barriers to advancing motor and sensory axons innervating the hindlimbs during chick development. Here we show that the vast majority of these carbohydrates are at the critical stage and location attached to the versican splice variants V0 and V1. We reveal that the isolated isoforms of this extracellular matrix proteoglycan suppress axon extension at low concentrations and induce growth cone collapse and rapid retraction at higher levels. Moreover, we demonstrate that versican V0 and/or V1, recombinantly expressed in collagen-I gels or ectopically deposited in the hindlimbs of chicken embryos in ovo, cause untimely defasciculation and axon stalling. Consequently, severe disturbances of nerve patterning are observed in the versican-treated embryos. Our experiments emphasize the inhibitory capacity of versicans V0 and V1 in axonal growth and evidence for their function as basic guidance cues during development of the peripheral nervous system.

\section{Introduction}

The establishment and stabilization of the neuronal circuitry during development and postnatal maturation greatly relies on a timely and spatially coordinated program regulating the delicate balance between axon growth promotion and inhibition. In the developing peripheral nervous system (PNS), the delineation of barrier tissues blocking axonal growth and forcing advancing axons into their designated trajectories constitutes one of the initial steps of the highly complex guidance process (Tosney, 1991). This early phase of motor and sensory innervation is at least partly accompanied by the selective deposition and turnover of inhibitory extracellular matrices (ECMs). Once pioneering axons have begun to invade permissive mesenchymal tissues and successive nerve fibers have followed by fasciculation, a refined system of diffusible and stationary attractants and repellents in combination with specific receptor sets on the advancing growth cones controls numerous branch point decisions and directs segregating axons toward their individual targets (Landmesser, 2001; Hanson et al., 2008).

The nonpermissive mesenchymal tissues, consistently bordering the pathways of migratory neural crest cells and growing

Received Sept. 17, 2010; revised Jan. 17, 2011; accepted Feb. 8, 2011.

Our work has been financed in part by grants from the Swiss National Science Foundation (D.R.Z., E.T.S.) and the Velux Foundation (D.R.Z.). We thank Marie-Therese Abdou for preparing the tissue sections, Beat Kunz for practical help and excellent advice, and Holger Moch and Philipp U. Heitz for their constant support during this project.

${ }^{*}$ E.T.S. and D.R.Z. contributed equally to this work.

Correspondence should be addressed to Dieter R. Zimmermann, Institute of Surgical Pathology, University Hospital Zürich, Schmelzbergstrasse 12, CH-8091 Zürich, Switzerland. E-mail: dieterzi@pathol.uzh.ch.

S. Dutt's present address: Tata Memorial Centre/Advanced Centre for Treatment, Research, and Education in Cancer, Navi Mumbai 410210, India.

M. Matasci's present address: Laboratory of Cellular Biotechnology, École Polytechnique Fédérale de Lausanne, CH-1015 Lausanne, Switzerland.

DOI:10.1523/JNEUROSCI.4897-10.2011

Copyright $\odot 2011$ the authors $\quad 0270-6474 / 11 / 315262-09 \$ 15.00 / 0$ axons during early PNS development, are particularly rich in chondroitin sulfate proteoglycans (CSPGs) and peanut agglutinin (PNA)-binding glycoproteins (Tosney and Landmesser, 1985; Oakley and Tosney, 1991). In the trunk of the chicken embryo, these temporary boundaries include the posterior sclerotome, the perinotochordal region, and the early subectodermal zone. CSPGs are also abundantly expressed in the developing hindlimbs. The early limb bud tissue blocks innervation initially in its entirety and delays axonal extension from the plexus region by $\sim 24 \mathrm{~h}$ (Wang and Scott, 2000). After this period, most of the nonpermissive areas have regressed and are ultimately confined to the condensing mesenchyme of the pelvic girdle and other pre-chondrogenic areas.

Prominently represented in all these transient barriers of the trunk and limb anlage are the two largest splice variants of the extracellular matrix CSPG versican, V0 and V1 (Landolt et al., 1995). Intriguingly, other members of the lectican/hyalectan family of CSPGs, including the smaller versican isoform V2, are similarly expressed in nonpermissive tissues of the developing or mature CNS and exert potent axon growth inhibitory activity (Bandtlow and Zimmermann, 2000; Schmalfeldt et al., 2000; Zimmermann and Dours-Zimmermann, 2008). Despite this apparent analogy to axon growth-suppressing roles of CSPGs in the CNS, a functional link between the selective expression and turnover of versican V0 and V1 and the nonpermissive character of matrices flanking axon trajectories during PNS formation has not been established so far.

Therefore, we have isolated intact versican V0 and V1, explored their inhibitory potential in a series of functional analyses with dorsal root explants in vitro, and analyzed their impact on axonal patterning in the developing limb by ectopical deposition in vivo. 


\section{Materials and Methods}

Antibodies and versican preparations. Polyclonal antibodies against specific domains of bovine, human, mouse, and chick versican were affinity purified from rabbit antisera prepared previously by our laboratory (Zimmermann et al., 1994; Landolt et al., 1995; Schmalfeldt et al., 1998, 2000). The anti-proteoglycan $\Delta$ Di-6S monoclonal antibody 3-B-3 was obtained from Seikagaku. The monoclonal antibody RMO-270 against neurofilament-160 kDa (anti-NF-M) (Invitrogen) and goat polyclonal antibodies against axonin-1 (Ruegg et al., 1989) were used for axon and growth cone labeling. Lectin staining of tissue sections was done with PNA and goat anti-PNA antibodies (both from Vector Laboratories). Fluorescent secondary antibodies included (1) Alexa Fluor-488 goat anti-rabbit IgG and Alexa Fluor-594 goat anti-mouse IgG for cell culture stainings, (2) Alexa Fluor-488 donkey anti-rabbit IgG, Alexa Fluor-555 donkey antimouse IgG, and Alexa Fluor-647 donkey anti-goat IgG (Invitrogen) for triple stainings of tissues sections, and (3) cyanine 3 (Cy3)-labeled goat anti-mouse secondary antibodies (Jackson ImmunoResearch) for wholemount NF stainings, respectively. Secondary antibodies for immunoblotting experiments were also from Jackson ImmunoResearch.

Versican isoforms used in the in vitro and in vivo studies were purified from conditioned medium of the human glioma cell line U251MG and from calf aorta as described previously (Dutt et al., 2006). Versican core glycoproteins used in some experiments were obtained by removal of the glycosaminoglycan chains through digestion with chondroitinase $\mathrm{ABC}$ (Seikagaku).

Blotting techniques. Extracts from Hamburger and Hamilton stage 21 to 22 (HH21/22, (Hamburger and Hamilton, 1951) chick trunks and hindlimbs, conditioned media from embryonic day 13 (E13) chick embryonic fibroblast, and U251MG cell cultures as well as control extracts of postnatal day 30 (P30) brains of wild-type and versican V0/V2 knockout mice (Dours-Zimmermann et al., 2009) were analyzed by lectin and immunoblotting. Samples were run on $4-15 \%$ Phastgels (GE Healthcare) and processed according to Zimmermann et al. (1994). For the detection of PNA-binding proteins, proteoglycans, and versicans, we used a DIG-Glycan Differentiation kit (Roche Applied Science), a monoclonal antibody against chondroitin sulfate stubs or our polyclonal antibodies against versican, respectively.

Neurite outgrowth assays. Stripe-choice analyses of neurites extending from intact or dissociated explants of dorsal root ganglia (DRG) of E10E11 chick embryos were essentially done as described (Vielmetter et al., 1990; Schmalfeldt et al., 2000). In brief, surface-treated glass coverslips were coated in alternating stripes covered with either test substrates admixed to $100 \mu \mathrm{g} / \mathrm{ml}$ laminin-1 or with $20 \mu \mathrm{g} / \mathrm{ml} \mathrm{laminin}-1$ alone (Invitrogen). The test substrate solutions contained, apart from laminin-1, intact or chondroitinase $\mathrm{ABC}$-digested versican $\mathrm{V} 1$ or a versican $\mathrm{V} 0 / \mathrm{V} 1$ mixture at concentrations of $10-100 \mu \mathrm{g} / \mathrm{ml}$. The DRGs were placed onto the stripe pattern and cultured in DMEM/F-12 1:1 medium containing $10 \% \mathrm{FCS}, 2 \%$ chicken serum, $100 \mathrm{U} / \mathrm{ml}$ penicillin, $100 \mu \mathrm{g} / \mathrm{ml}$ streptomycin, $100 \mathrm{ng} / \mathrm{ml}$ nerve growth factor 7S (all from Invitrogen), $10 \mathrm{~mm}$ cytosine arabinoside, and $0.5 \%$ methylcellulose (both from Sigma). After $2-3 \mathrm{~d}$ of incubation in a $5 \% \mathrm{CO}_{2}$ atmosphere at $37^{\circ} \mathrm{C}$, the explant cultures were fixed in $4 \%$ paraformaldehyde $/ 0.33 \%$ sucrose in PBS for $10 \mathrm{~min}$ and subsequently analyzed by immunofluorescence. For some experiments, laminin-1 was replaced by fibronectin (Roche Diagnostics) as neurite growth-supporting substrate.

To test growth cone behavior in time-lapse video microscopy, half of a pretreated glass coverslip was first manually covered with a mixture of $100 \mu \mathrm{g} / \mathrm{ml}$ versican V0/V1 and $100 \mu \mathrm{g} / \mathrm{ml} \mathrm{laminin}-1$, followed by coating of the remaining surface with $20 \mu \mathrm{g} / \mathrm{ml}$ laminin-1 alone. The border of the test substrate area was delineated on the back of the slide with a marker pen. DRGs from E10 chick embryos were placed near the versican-coated area, and neurites were allowed to grow under a Leica DM IRBE wide-field microscope equipped with a culture chamber controlling temperature and $\mathrm{CO}_{2}$ conditions $\left(37^{\circ} \mathrm{C}\right.$ and $\left.5 \%\right)$. Images of growth cone movement toward the versican-coated region were captured with a Hamamatsu Orca ER camera using a phase-contrast PH1 N Plan L 20×/0.40 objective. Frames were captured every $30 \mathrm{~s}$ and analyzed with the Openlab 3.1.5 software.

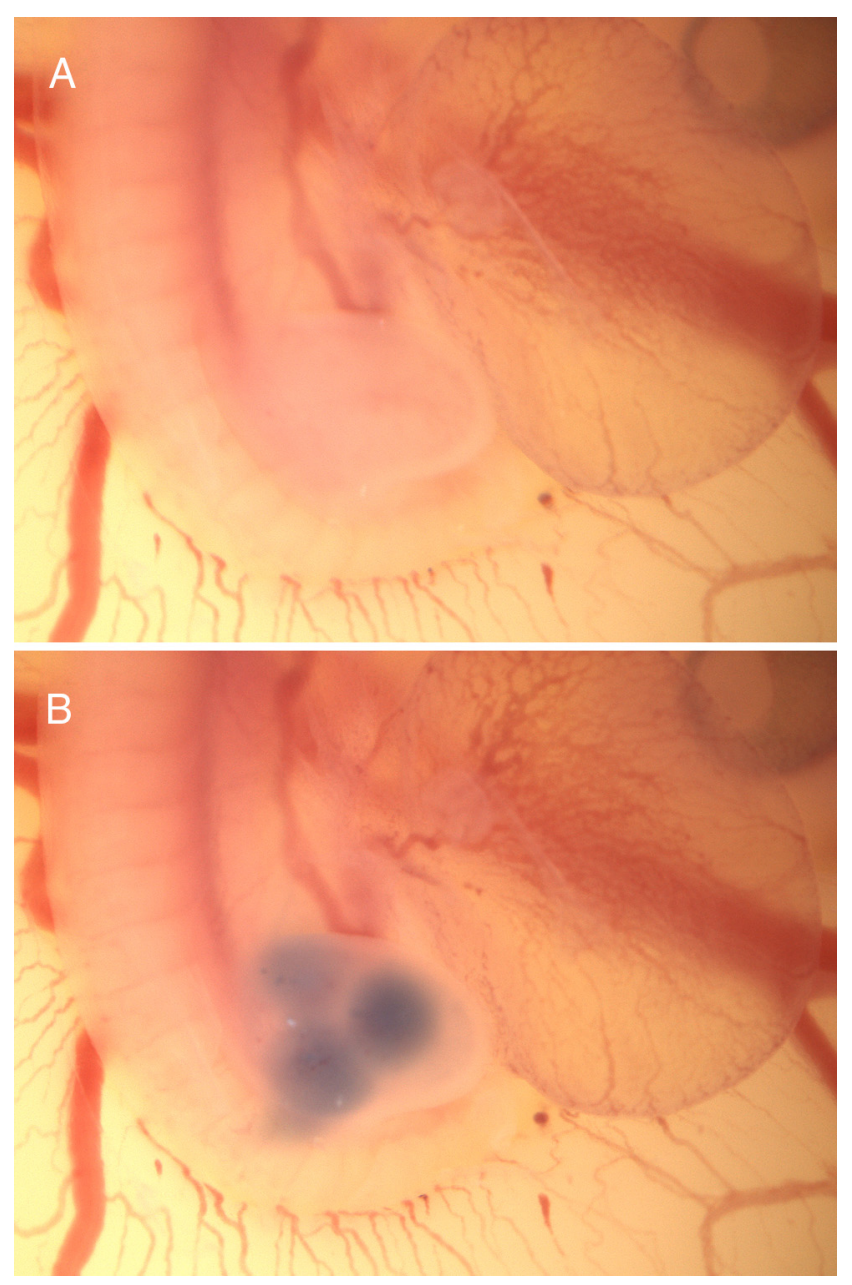

Figure 1. Chick embryo at $\mathrm{HH} 21 / \mathrm{HH} 22$ before $(\boldsymbol{A})$ and after $(\boldsymbol{B})$ in ovo injection of the trypan blue-containing versican solution.

Cocultures of DRGs and transfected COS cells. COS cells were transiently transfected with either an empty pSecTagA vector (Invitrogen) (mock transfection) or with a pSecTagA construct, in which the reconstituted full-length cDNA of the mature human versican V1 core protein including its native stop codon had been inserted into the vector after the Ig $\kappa$ secretory leader sequence (Zimmermann and Ruoslahti, 1989). COS cell aggregates were prepared in hanging drops as described (Kennedy et al., 1994). For cocultures, COS cell aggregates were placed in solidifying collagen-I gels in close vicinity to DRGs from E10 chick embryos (Lumsden and Davies, 1983) and subsequently incubated at $37^{\circ} \mathrm{C}$ in DMEM/F-12 (1:1) medium containing 10\% FCS, $2 \%$ chicken serum, 2 mm L-glutamine, 100 $\mathrm{U} / \mathrm{ml}$ penicillin, $100 \mu \mathrm{g} / \mathrm{ml}$ streptomycin, and $100 \mathrm{ng} / \mathrm{ml} \mathrm{7S} \mathrm{NGF} \mathrm{(all} \mathrm{from}$ Invitrogen). After 3.5-4 d, the three-dimensional cultures were fixed in $4 \%$ paraformaldehyde $/ 0.33 \%$ sucrose in PBS and processed for immunofluorescence staining.

In ovo injections of versican. Hisex chick embryos were staged according to Hamburger and Hamilton (1951). In ovo injections were performed as described previously (Stoeckli and Landmesser, 1995). After local removal of the extra-embryonic membrane, injections into the hindlimb were done with a pointed glass capillary (tip diameter of $\sim 5$ $\mu \mathrm{m})$ attached to Teflon tubing. The test substrates in PBS were mixed with trypan blue (final concentration $0.04 \% \mathrm{v} / \mathrm{v}$; Invitrogen) to control localization and volume of the injection. Injections were done into the right hindlimb at three different positions near the plexus region, two paraxial and one distal (Fig. 1). Less than $1 \mu \mathrm{l}$ of the test solution with versican concentrations of 180 or $400 \mu \mathrm{g} / \mathrm{ml}$ (V1 and V0/V1 preparations, respectively) was deposited at each time point. First injections were done at $\mathrm{HH} 18-\mathrm{HH} 19$ and subsequently repeated in regular in- 
tervals for three to four times until the embryo reached $\mathrm{HH} 22-\mathrm{HH} 23$. After every manipulation, the eggs were resealed with paraffin and a glass coverslip and incubated at $39^{\circ} \mathrm{C}$. At the end of the in ovo experiment (HH25/HH26), embryos were collected, eviscerated, freed of residual blood, and fixed in $4 \%$ paraformaldehyde before wholemount staining.

Immunohistological and lectin staining procedures. For the combined immunofluorescence and PNA stainings of chick embryo sections, we adapted previously described protocols (Oakley and Tosney, 1991; Schmalfeldt et al., 2000). In brief, the isolated embryos were fixed overnight in $4 \%$ paraformaldehyde containing $0.5 \%$ cetylpiridinium chloride, dehydrated, and paraffin embedded. Glass slides carrying $4-\mu \mathrm{m}$-thick tissue sections were dewaxed, and antigens were retrieved in $10 \mathrm{~mm}$ trisodium citrate, $\mathrm{pH}$ 6.0, under controlled conditions (antigen-retrieval device FSG 120-T/T; Milestone). Sections were then blocked with CarboFree blocking solution for $90 \mathrm{~min}$ and incubated with $10 \mu \mathrm{g} / \mathrm{ml} \mathrm{PNA} \mathrm{in} 10 \mathrm{~mm}$ HEPES, $150 \mathrm{~mm} \mathrm{NaCl}$, and $1 \mathrm{~mm} \mathrm{CaCl}_{2}$, pH 7.5 for $3 \mathrm{~h}$ (all PNA-staining reagents from Vector Laboratories). The binding of the primary antibodies in PBS containing 0.5\% BSA, $0.2 \%$ gelatin, and $0.02 \% \mathrm{NaN}_{3}$ was allowed to proceed overnight at $4^{\circ} \mathrm{C}$. The antibody dilutions were 1:400 for anti-PNA, 1:500 for the antibodies against versican GAG- $\beta$, and 1:2000 against neurofilament-M. The subsequent incubation with Alexa Fluor-labeled secondary antibodies (all 1:200 dilution; Invitrogen) for 1-2 $\mathrm{h}$ was in some experiments followed by counterstaining with Hoechst H33258 bis-benzimide (Invitrogen). Primary and secondary antibody binding of fixed dorsal root ganglia explant cultures was done analogously, but antibodies were directly applied after initial blocking with $0.5 \%$ BSA, $0.2 \%$ gelatin, and $0.02 \% \mathrm{NaN}_{3}$ in PBS (Schmalfeldt et al., 2000). Stained cell cultures and tissue sections were finally mounted in fluorescence mounting medium (Dako).

For whole-mount staining of nerve fibers, fixed embryos were washed in PBS and permeabilized in 1\% Triton X-100/PBS for $1 \mathrm{~h}$ at room temperature. After rinsing in PBS, they were incubated for $1 \mathrm{~h}$ in $20 \mathrm{~mm}$ lysine, $0.1 \mathrm{M}$ sodium phosphate, $\mathrm{pH} 7.4$, subsequently washed five times in PBS for $10 \mathrm{~min}$, and subjected to blocking in 10\% fetal calf serum/PBS for at least $2 \mathrm{~h}$ at room temperature. Incubation with the monoclonal antibody against neurofilament-M (dilution 1:1500) was performed for $48 \mathrm{~h}$ at $4^{\circ} \mathrm{C}$. After five short and one last prolonged incubation in PBS ( $\geq 12 \mathrm{~h}$ ), embryos were again submerged in blocking buffer for $2 \mathrm{~h}$ before binding of Cy3-labeled secondary antibodies (diluted 1:500) overnight at $4^{\circ} \mathrm{C}$. Unbound antibodies were removed by six extensive PBS washing steps at room temperature (at least two times for $>2 \mathrm{~h}$ plus last incubation overnight). Finally, the embryos were dehydrated in an increasing methanol series $(25,50,75$, and $100 \%$; each step for $\geq 30 \mathrm{~min})$ and then transferred into 2:1 benzyl benzoate/benzyl alcohol.

Fluorescence photomicrographs were taken with an Olympus BX61 (cells/sections) or a SZX12 microscope (whole mounts) equipped with a F-view camera. Image capture and analysis was performed using the AnalySISPro software (Soft Imaging System). Monochromatic fluorescence images were imported into separate color channels in Photoshop and superimposed.
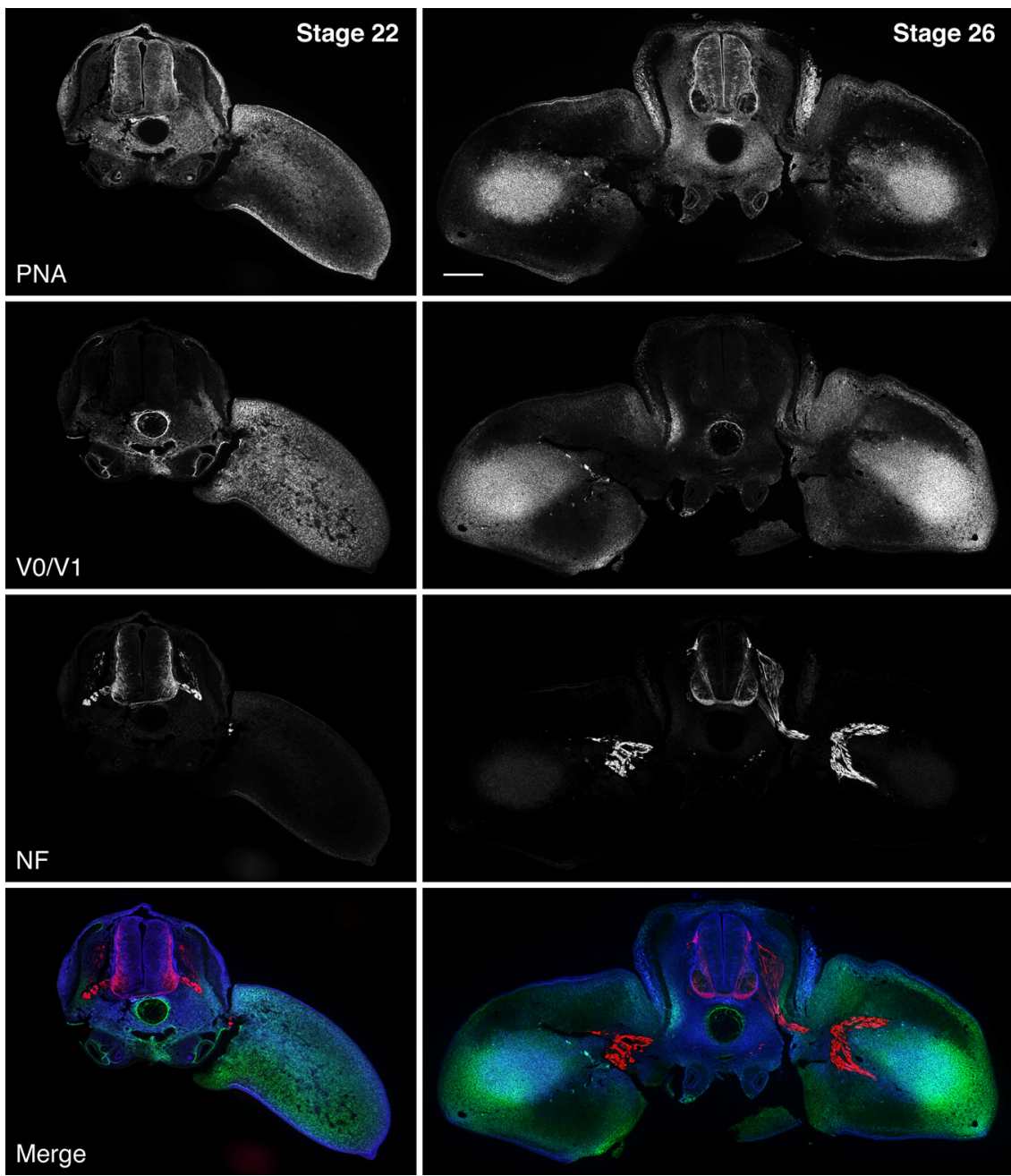

Figure 2. Temporospatial relationship of PNA-binding sites, versican V0/V1, and axonal growth in the developing hindlimb 作 forming dermis, and the condensing mesenchyme adumbrating the future leg bones. Scale bar, $200 \mu \mathrm{m}$.

\section{Results}

Independent histological studies by Oakley and Tosney and by our group have previously revealed strict complementarities between axonal growth patterns and the distribution of PNAbinding carbohydrates, chondroitin-6-sulfate (Oakley and Tosney, 1991), and the versican isoforms V0/V1 (Landolt et al., 1995) during motor and sensory innervation of the trunk and limbs in the chicken. Although the originally monochrome stainings were suggestive of a close association of these mesenchymal components with axon growth-impeding boundary tissues, particularly the interconnection between the PNA-binding molecule and the chondroitin sulfate-carrying versicans remained rather obscure. For this reason, we have first attempted to clarify this relationship before embarking on extensive functional studies in vitro and in vivo.

\section{Versicans are the major PNA-binding proteins in the developing trunk and limb buds}

Our triple fluorescence stainings simultaneously detecting PNAbinding carbohydrates, versicans $\mathrm{V} 0 / \mathrm{V} 1$, and neurofilaments 


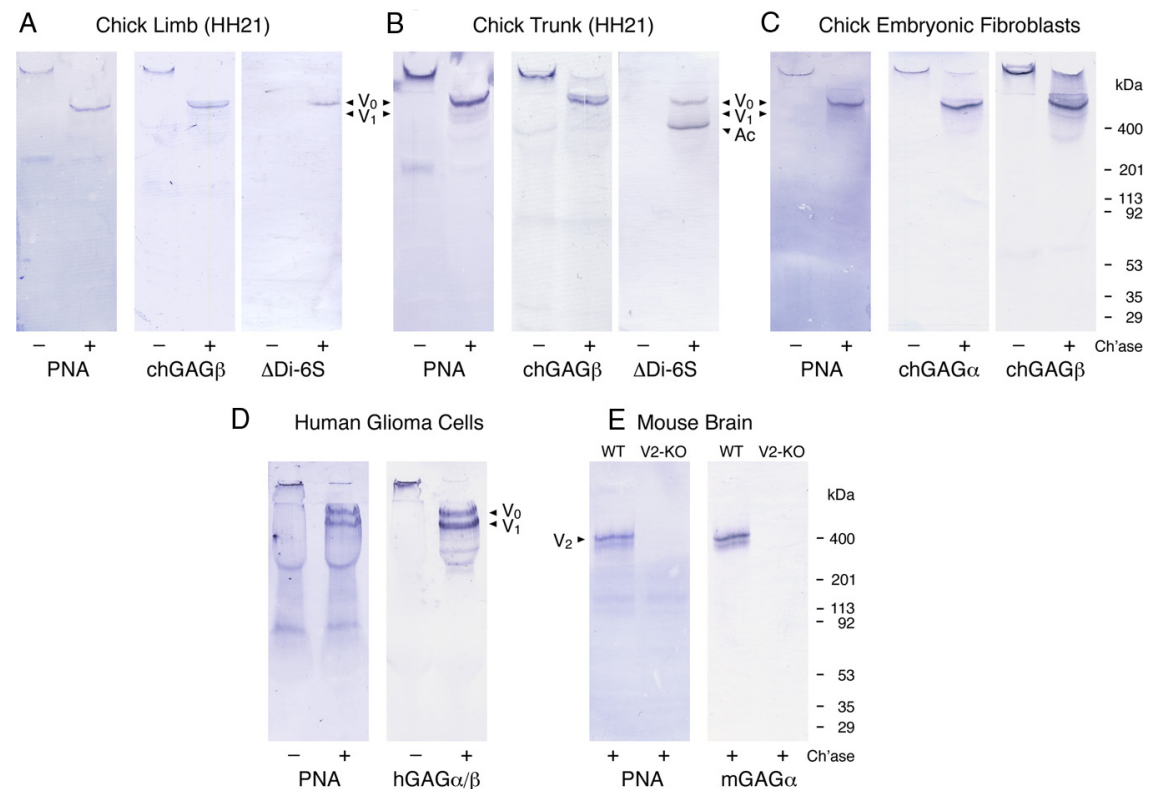

Figure 3. Identification of versicans as major PNA-binding proteins. Extracts of hindlimbs $(\boldsymbol{A})$ and trunks $(\boldsymbol{B})$ from $\mathrm{HH} 21$ chick embryos, supernatants of chick embryonic fibroblasts $(\boldsymbol{C})$, and of human U251 glioma cell cultures $(\boldsymbol{D})$ and brain extracts of P30 wild-type (WT) and versican V0/V2 knock-out mice ( $\boldsymbol{E} ; \mathrm{KO}$ ) were analyzed by lectin and immunoblotting with PNA and antibodies against versicans and against chondroitin-6-sulfate stubs ( $\triangle \mathrm{Di}-6 \mathrm{~S})$, respectively. Some of the samples were digested with chondroitinase $A B C(+)$ to remove the $G A G$ side chains. The domain-specific antibodies against versican are reactive with the chick variants V0/V1 (chGAG $\beta$ ), the chick and mouse is oforms V0/V2 (chGAG $\alpha, \mathrm{mGAG} \alpha$ ), or all proteoglycan variants of human versican $(\mathrm{hGAG} \alpha / \beta)$. The bands of the different core glycoproteins of versicans (V0, V1, and V2) and of aggrecan (Ac) are indicated by arrowheads.

now clearly demonstrate a broad overlap of versican-specific immunoreactivity and PNA-binding sites in mesenchymal barriers and confirm the virtual absence of both components from the axonal pathways in the chick embryonic trunk and the developing hindlimbs (Fig. 2). For instance, at stage $\mathrm{HH} 22$, when the growing motor and sensory axons have joined but are still locked within the plexus region, the entire hindlimb is intensely labeled by both PNA-lectin and versican-specific antibodies. At this time, considerable versican V0/V1 depositions are also found in the perinotochordal region, particularly in immediate vicinity to the notochord, whereas the staining of the PNA-lectin in this area appears more uniform and widespread. Unlike versican, PNA binding is additionally detected within the neural tube and in the ectodermal layer. Later in hindlimb development (HH26), versican and the PNA-binding carbohydrate become confined to the pelvic girdle, to the subectodermal region, and to the condensing mesenchyme of the pre-chondrogenic zones. The trajectories of the advancing nerve fibers and the more distal areas of future axonal invasion are essentially free of PNA and versican staining. Although PNA-binding carbohydrates are still present in the perinotochordal region, the versican V0/V1 immunoreactivity has greatly diminished in this area. At this stage, the PNA-binding activity also persists in the neural tube (except for the motor columns) and in the ectoderm.

The rather striking colocalization of PNA-binding molecules and the versican immunoreactivity within the early mesenchyme supports the hypothesis that the highly glycosylated versicans $\mathrm{V} 0$ and V1 might carry not only chondroitin sulfate but also galactosyl $(\beta-1,3) N$-acetylgalactosamine, the oligosaccharide recognized by PNA. We have therefore extracted early embryonic trunks and hindlimb buds (HH21/HH22) with a detergentcontaining high-salt buffer to solubilize extracellular matrix and cell surface molecules, and we have subsequently performed
PNA-lectin blotting and versican V0/V1specific immunoblotting (Fig. 3). Comparisons of these analyses demonstrate that versicans, and in particular the V0 isoform, in fact account for most of the PNA-binding activity in the early chick trunk and limb extracts. Moreover, nearly exclusive staining of versican $\mathrm{V} 0$ and $\mathrm{V} 1$ is observed on PNA-lectin blots of conditioned culture media from chick primary embryonic fibroblasts and from the human glioma cell line U251. Akin to the larger V0 and V1 isoforms, versican V2 seems to represent the major PNAbinding component of the mature CNS, because brain extracts of knock-out mice selectively lacking this isoform (DoursZimmermann et al., 2009) have lost virtually all of the PNA reactivity along with the V2 variant.

\section{Versican V0 and V1 are potent neurite outgrowth inhibitors in vitro}

To examine the inhibitory capacity of the large versican isoforms, we have performed various functional assays with chick DRG explants in vitro. In stripechoice experiments, we have first exposed the outgrowing sensory axons to alternating lanes coated either with the neurite growth-promoting ECM-glycoprotein laminin-1 alone or with mixtures of laminin-1 and intact versican V1 or versican V0/V1 preparations isolated as described (Dutt et al., 2006). Despite the high laminin level present on both surfaces, robust extension of DRG neurites is confined to the substrate stripes that lack versican (Fig. 4). Versican overrides the axon growth-promoting activity not only of laminin-1. Similar inhibitions can also be observed, when fibronectin (Fig. 5) or collagen-I (data not shown) are used as growth-promoting substrates in this assay. Because laminin-1 is the most effective substrate and therefore widely used for in vitro studies, we have performed the subsequent stripe-choice experiments with this standard neurite outgrowth promoter. Even under these optimal conditions, a partial reversion of the laminin-induced growth can already be observed, when as little as $10 \mu \mathrm{g} / \mathrm{ml}$ versican V1 or V0/V1 mixture is included in the $100 \mu \mathrm{g} / \mathrm{ml}$ laminin coating solution (Fig. 6). At versican concentrations of $25-50 \mu \mathrm{g} / \mathrm{ml}$, the avoidance by the neurites is nearly complete. This inhibitory activity of versican V0 and V1 is reduced, but not abolished, when the chondroitin sulfate side chains are removed by chondroitinase $\mathrm{ABC}$ digestion. Compared with the intact proteoglycan preparations, the coating concentrations of the core glycoproteins have to be approximately doubled to achieve similar axonal avoidance reactions.

Although lower versican V0 and V1 concentrations may provoke stalling and/or turning of the axonal tip, higher concentrations induce growth cone collapse and rapid retraction. We have recorded this latter behavior by time-lapse video microscopy (Fig. 7), in which we confronted DRG neurites growing on a 100 $\mu \mathrm{g} / \mathrm{ml}$ coat of laminin- 1 to a surface treated with laminin- 1 and versican V0/V1 at dilutions of $100 \mu \mathrm{g} / \mathrm{ml}$ each. In these experiments, the neurites advance on the laminin-1 substrate at a speed of $120-150 \mu \mathrm{m} / \mathrm{h}$ and display extended growth cone morphologies. Once they have contacted the versican-containing zone, 

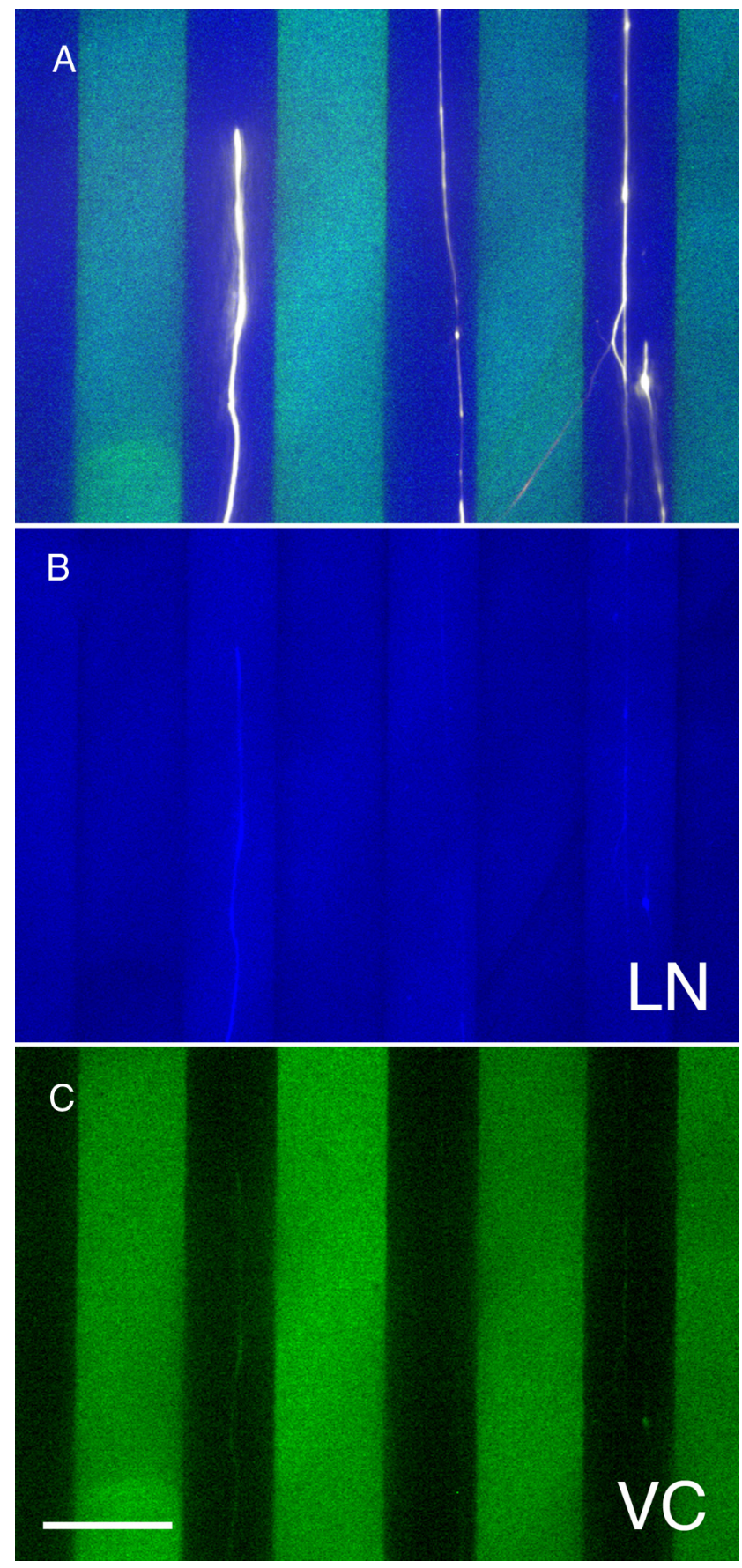

Figure 4. Versican overrides the neurite growth-promoting activity of laminin-1 in a stripe-choice assay. $A$, Overlay of false color images of a triple immunofluorescence staining of laminin-1 (LN; blue), versican (VC; green), and neurofilaments (white). Despite the rather uniform distribution of the growth-promoting substrate laminin-1, neurites from E10 chick dorsal root ganglions avoid stripes coated with laminin-1 plus versican V0/V1 (100 $\mu \mathrm{g} / \mathrm{ml}$ coating concentration) and advance on lanes coated with laminin-1 alone. The laminin- and the versican-specific stainings are also depicted separately in $\boldsymbol{B}$ and $\boldsymbol{C}$, respectively. Scale bar, $50 \mu \mathrm{m}$.

however, the growth cones immediately collapse and the axons retract with a three to four times higher velocity. This retrograde movement slows down after a while and then stops, the growth cones restore, and axonal growth is reinitiated. Similarly, growth cones advancing on laminin-1 alone in the stripe-choice format constantly explore the neighboring lanes containing high versi-

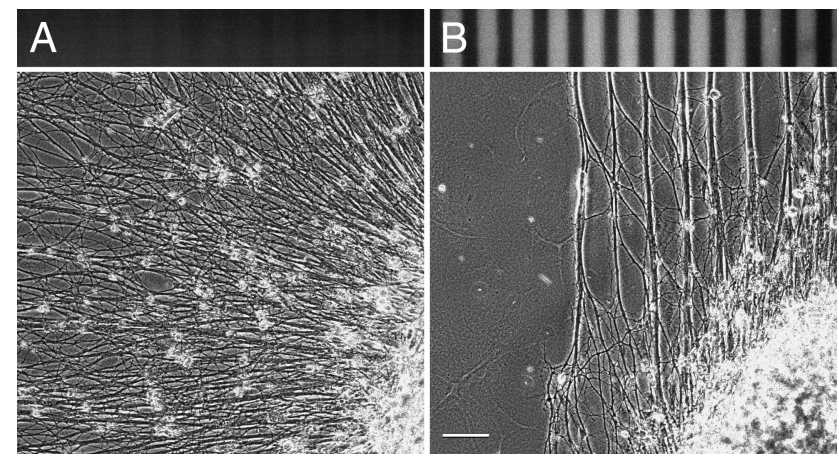

Figure 5. Versican-mediated inhibition of neurite outgrowth on fibronectin. Although neurites from an E10 chick dorsal root ganglion extend freely on alternating substrate stripes coated with 20 and $100 \mu \mathrm{g} / \mathrm{ml}$ fibronectin $(\boldsymbol{A})$, they are rapidly forced into versican-free lanes on alternating stripes of fibronectin alone (coated with $20 \mu \mathrm{g} / \mathrm{ml}$ ) and fibronectin plus versican V0/V1 (100 $\mu \mathrm{g} / \mathrm{ml}$ each) substrates (B). Phase-contrast and versican-specific immunofluorescence images. Scale bar, $100 \mu \mathrm{m}$.

can concentrations but invariably collapse when they reach the end of the versican-free lane (Fig. 7).

In the final experiments of our in vitro series, we have analyzed the influence of versican deposition on axonal growth in threedimensional collagen-I matrices. Also in this more in vivo-like setting, we obtained clear evidence for a dominant inhibitory effect of versican overriding the axon growth promotion, this time exerted by the collagen substrate. In the collagen gel assay (Fig. 8), axons frequently extend from the DRG explants in the form of robust nerve bundles. However, as soon as they approach the neighborhood of COS cells, which recombinantly express full-length versican V1, they begin to defasciculate and then stop before reaching the aggregates. In contrast, mock-transfected control aggregates devoid of versican expression do not affect neurite outgrowth.

\section{Ectopical deposition of versican V0 and V1 disturbs axon patterning in developing hindlimbs in vivo}

Untimely defasciculation and aberrant axon routings are also observed in vivo, when versican $\mathrm{V} 1$ or $\mathrm{V} 0 / \mathrm{V} 1$ are ectopically deposited in the nerve pathways of the developing hindlimb. Repeated in ovo injections of versicans between $\mathrm{HH} 18$ and $\mathrm{HH} 23$ resulted in aberrant branching of developing peripheral nerves at $\mathrm{HH} 25 / \mathrm{HH} 26$. Whole mounts stained with anti-neurofilament antibodies were scored blind to the experimental condition for axonal branching in the developing hindlimbs (Fig. 9). As main indicators, we scored abnormal exit points (criterion 1) and irregular branching of secondary nerve fibers (criterion 2) emerging from the dorsal trunk of the sciatic plexus. This way, we revealed moderate to severe disturbances (only one or both criteria fulfilled, respectively) of axonal growth behavior in the vast majority of the embryos, in which the natural formation of versican-free pathways was counteracted by our exogenous versican supply. Conversely, irregularities of sciatic nerve formation were only very rarely seen in control-injected embryos by the three independent observers of this blinded study.

In summary, all our analyses emphasize the inhibitory potential of versican V0 and V1 in axon growth regulation by inducing defasciculation, deflection, and repulsion of neuronal processes depending on the concentration within the extracellular matrix. 
Controls

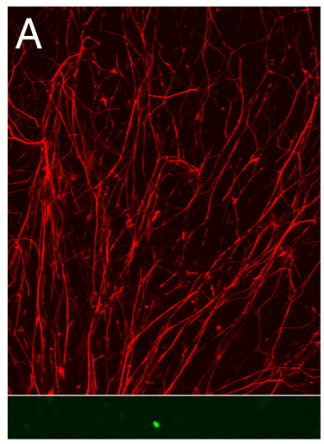

$1.06 \pm 0.22$

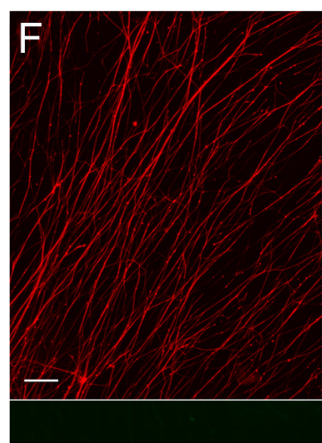

$1.06 \pm 0.18$

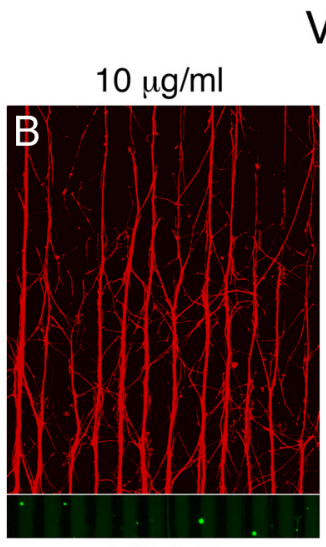

$2.88 \pm 0.88$

$10 \mu \mathrm{g} / \mathrm{ml}$

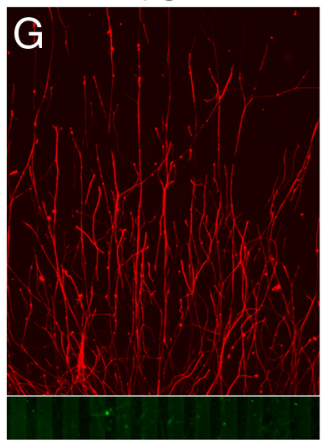

$1.66 \pm 0.48$
V1

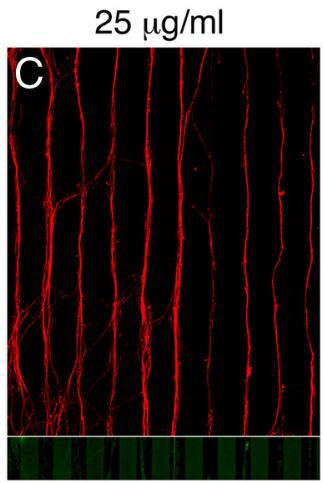

$8.59 \pm 2.58$

$25 \mu \mathrm{g} / \mathrm{ml}$

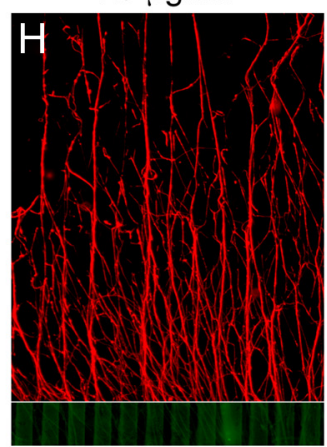

$2.09 \pm 0.36$

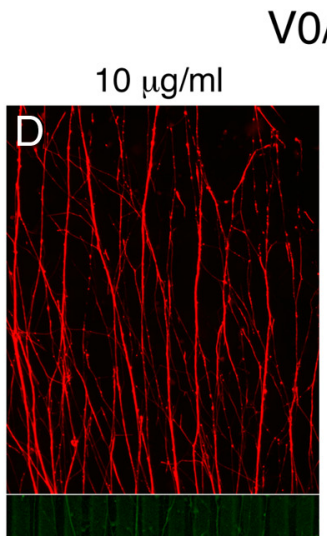

$1.18 \pm 0.49$

$10 \mu \mathrm{g} / \mathrm{ml}$

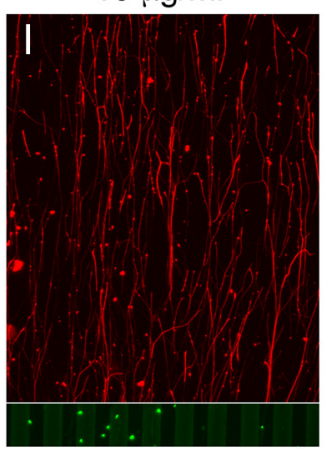

$1.26 \pm 0.37$
V0/V1

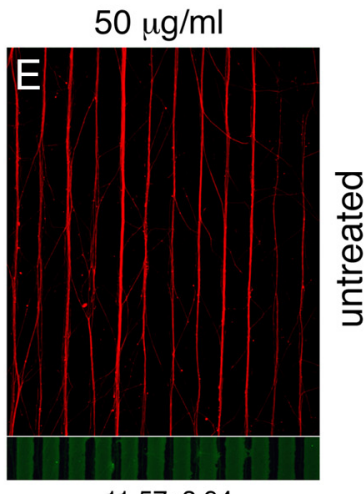

$11.57 \pm 3.94$

$50 \mu \mathrm{g} / \mathrm{ml}$

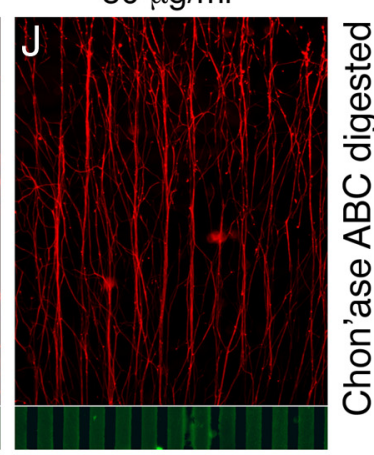

$2.61 \pm 0.77$

Figure 6. Inhibitory potential of versican V0/V1 on neurite outgrowth in stripe-choice assays. Neurites from E10 chick dorsal root ganglions grow on laminin-1 stripes but avoid alternating lanes coated with laminin-1 plus intact or core glycoprotein preparations of versican V1 ( $\boldsymbol{B}, \boldsymbol{C}$ and $\boldsymbol{G}, \boldsymbol{H}$, respectively) or of a V0/V1 mix ( $\boldsymbol{D}, \boldsymbol{E}$ and $\boldsymbol{I}, \boldsymbol{J})$. For the coating of the test stripes, a $100 \mu \mathrm{g} / \mathrm{ml}$ laminin-1 solution was supplemented with variable amounts of versican. The corresponding versican concentrations are indicated above the panels. On the versican-free control lanes, $20 \mu \mathrm{g} / \mathrm{ml}$ laminin-1 was applied. The stripe patterns of the control assays $(\boldsymbol{A}, \boldsymbol{F})$ were prepared analogously, but versican was omitted in the test stripes; control $(\boldsymbol{F})$ included in addition chondroitinase and enzyme buffer in the test lanes. Neurofilaments (red) and versican (green) have been visualized by double immunofluorescence staining. Ratios ( \pm SD) of averaged gray values of the axon-specific red fluorescence in versican-free versus the adjacent versican-containing lanes are shown below the panels. Scale bar, $100 \mu \mathrm{m}$.

\section{Discussion}

The guidance process that directs sensory and motor axons with utmost precision toward their individual targets in the hindlimb operates on multiple levels. At the lowest level, general cues divide the early mesenchyme into permissive and non-permissive areas for axon growth (Tosney, 1991; Landmesser, 2001). Through short-range contact, they roughly indicate the prospective nerve routes and transiently block inappropriate and/or premature innervation of differentiating tissues. Although the axons following these basic pathways intermingle initially in the spinal nerves, they subsequently segregate within the plexus region into separate pools, which already bear the capacity to later respond differentially to region-specific cues within the developing limbs. Rhythmic electrical bursts originating from the early spinal cord appear to sustain this axonal pooling and, hence, further influence subsequent pathfinding decisions (Hanson et al., 2008). Controlled by this second-level and more sophisticated guidance mechanism, axon bundles enter the hindlimb and stereotypically bifurcate into ventral and dorsal nerve trunks. More distally, the growth cones encounter several additional choice points, in which selected subsets of nerve fibers continue to branch off and finally defasciculate at their predetermined target destination. This last step of innervation is likely regulated by the most complex and hitherto still essentially unknown interplay of multiple receptors and corresponding guidance cues.

Commonly, the identification of guidance molecules that function at any stage of limb development has been rather diffi- cult. Best characterized so far are ligand-receptor systems that cooperate in dorsoventral pathfinding decisions at the entrance of the hindlimb. This includes pairs of ephrinA:EphA4 and ephrinB:EphB receptors controlling selective axonal growth by repulsion (Helmbacher et al., 2000; Eberhart et al., 2002; Luria et al., 2008) and the ligand-receptor combination of glial cell linederived neurotrophic factor:Ret mediating axon attraction (Kramer et al., 2006). Mice lacking one or several of these signaling components indeed display different degrees of misrouting of motor axons at the dorsoventral choice point, but the basic outline of the main nerve pathways remains unaffected (Helmbacher et al., 2000; Kramer et al., 2006; Luria et al., 2008). These findings clearly establish their role as specific cues, yet they indicate that other molecules operate on a more general level of axonal guidance.

As a result of their consistent association with barrier tissues, PNA-binding glycoproteins and chondroitin-6-sulfate-carrying proteoglycans have generally been considered the prime candidates for such a universal role, namely as inhibitors of neural crest cell migration and axonal growth in the periphery (Oakley and Tosney, 1991; Oakley et al., 1994). The best match in the search for the CSPG component is versican, because its splice variants $\mathrm{V} 0$ and V1 show a highly similar temporospatial distribution in the developing trunk and hindlimbs (Landolt et al., 1995) and because it impedes the migration of neural crest stem cells in vitro (Dutt et al., 2006). We now demonstrate that these two versican isoforms are also the main carriers of PNA-reactive carbohy- 
drates at the corresponding locations and therewith tie our versican findings to the knowledge of PNA-binding barrier components. This integration may as well encompass the only partly characterized growth cone collapse-inducing 48 and 55 $\mathrm{kDa}$ glycoproteins, which have been isolated previously by PNA affinity chromatography from extracts of cultured somitic strips (Davies et al., 1990). Considering our current lectin blots with almost exclusive staining of the versican core glycoproteins in embryonic trunk extracts, it appears unlikely that these former preparations of PNA-binding protein contained no versicans. They must have rather evaded detection as a result of their large sizes and dispersion in gel electrophoresis. It seems therefore likely that at least parts of the growth-cone-collapsing activity ascribed to these smaller PNA-binding glycoproteins has emanated from "contaminating" versicans. Whether the 48 and 55 $\mathrm{kDa}$ components represented chondroitin sulfate-free proteolytic fragments of versican remains presently open.

In a few tissues of the early trunk, such as the ectoderm and the neural tube, PNAbinding and versican V0/V1 immunostaining do not colocalize. Moreover, the initially expressed versicans, but not the PNA-affinity sites, disappear from the greater surrounding of the notochord after $\mathrm{HH} 22-\mathrm{HH} 23$. At this time and location, versican is progressively being substituted by its close relative aggrecan (Oettinger et al., 1985; Domowicz et al., 1995). Like versicans, it carries chondroitin sulfate side chains and numerous mucin-type O-glycans, some of which might maintain the PNA reactivity at this particular site. However, the early notochordal aggrecan of the trunk region seems to bind only little PNA according to our blotting experiments. Aggrecan and versican V0/V1 probably share some inhibitory functions during the initial stages of PNS formation. Although aggrecan may prevent neural crest cells and neuronal projections from invading the perinotochordal region (Perris and Johansson, 1990; Snow et al., 1990), versicans V0 and V1 seem to be primarily responsible for the nonpermissive properties of the posterior somite, the early limb bud, and pelvic girdle. Only later in development, when versican V0/V1 has long been cleared from the axonal pathways and when cartilage begins to form, aggrecan and some other chondroitin sulfate proteoglycans, such as decorin and type IX collagen, replace versican in the skeletal primordia of the limb (Shinomura et al., 1984; Lennon et al., 1991; Yamagata et al., 1993). Of note, defects in versican turnover lead at this advanced stage to digit malformations (McCulloch et al., 2009).

Despite their intriguing association with barrier tissues during nervous system development, the exploration of the putative
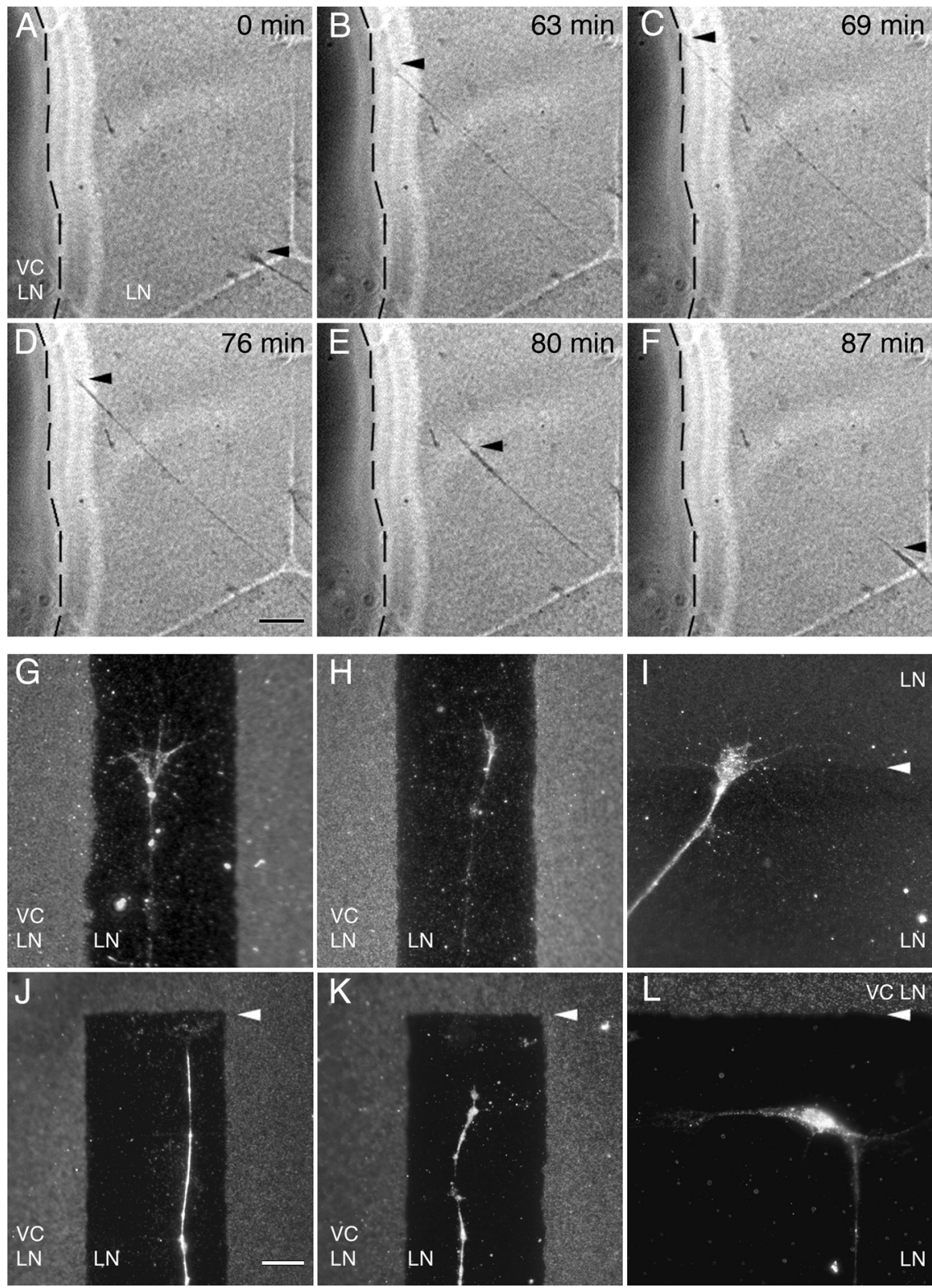

Figure 7. Growth cone collapse and retraction of DRG neurites after contact with versican-containing substrate. Still images from time-lapse video microscopy $(\boldsymbol{A}-\boldsymbol{F})$ documenting the axon growth behavior of E10 chick DRG axons on a laminin-1 (LN) substrate either containing or lacking versican V0/V1 (VC). The boundary to the area coated with laminin plus versican V0/V1 (100 $\mu \mathrm{g} / \mathrm{ml}$ each) is marked with a stippled line. At 0 and $63 \mathrm{~min}$, the growth cone (arrowhead) is moving forward in direction of the versican-containing region. Contacting versican after $69 \mathrm{~min}$, it collapses and the axon rapidly retracts back toward the cell body. After $87 \mathrm{~min}$, the original position is reached $(\boldsymbol{F})$. Scale bar: $\boldsymbol{A}-\boldsymbol{F}, 25 \mu \mathrm{m}$. Immunofluorescence overlays of substrate stainings of versican $(\boldsymbol{G}, \boldsymbol{H}, \boldsymbol{J}-\boldsymbol{L})$ or laminin-1 $(\boldsymbol{I})$ and axonin-1-specific neurite-labeling reveal growth cones with partly to fully extended structures during advancement on a versican-free zone between versican-containing stripes $(\boldsymbol{G}, \boldsymbol{H})$ or across the border of two differentially coated laminin-1 control areas $(I ; 100 \mu \mathrm{g} / \mathrm{ml}$ coating above and $20 \mu \mathrm{g} / \mathrm{ml}$ below arrowhead). A fully collapsed morphology is, however, invariably observed near the ends of versican-free lanes (arrowheads in $J, \boldsymbol{K}$ ). $\boldsymbol{L}$, A neuronal cell body near the versican-containing surface projects a long neurite perpendicularly away from versican, whereas a short second process extends strictly parallel to the border. Scale bar: $\mathbf{G}-\boldsymbol{L}, 10 \mu \mathrm{m}$.

guidance roles of the two largest versican variants has long been hampered by their extraordinary structural and biochemical properties. In addition, attempts to approach functional aspects by gene knock-out experiments in mice or by overexpression and knockdown in chick embryos have been frustrating as a result of the early lethality of versican null mice (Mjaatvedt et al., 1998) and the relative inefficiency of in ovo electroporation of mesenchymal cells in the early limbs, respectively (our unpublished observations). Only the recent elaboration of protocols to isolate 

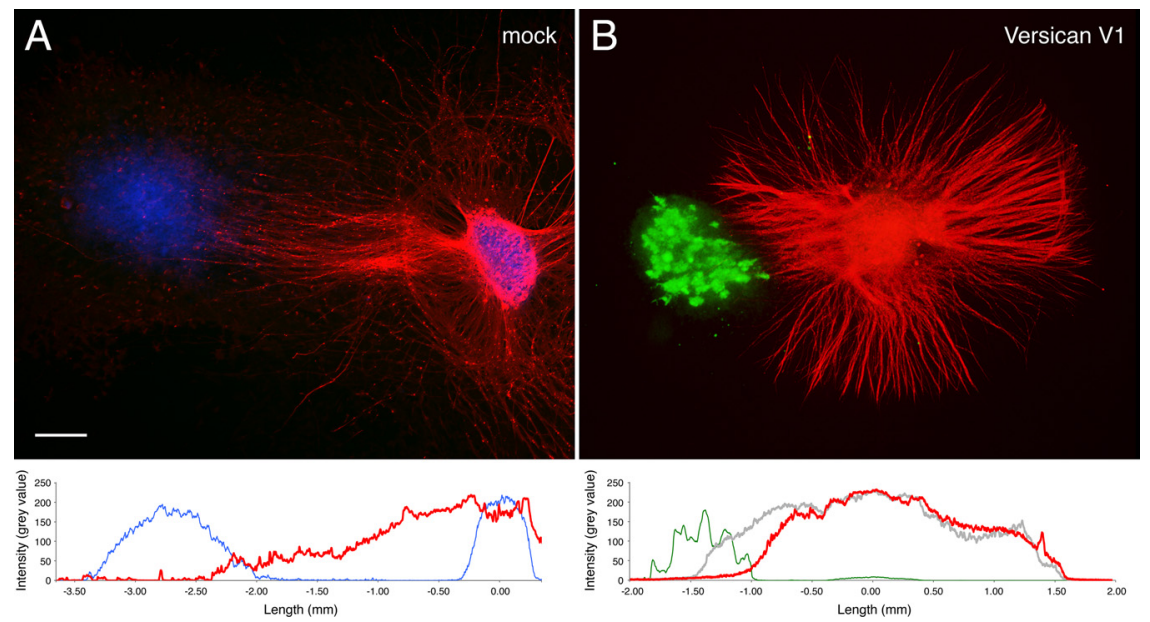

Figure 8. Inhibition of axonal outgrowth by versican V1-expressing COS aggregates in collagen-I gel. Neurites from E10 chick DRG extend radially within the collagen gel but defasciculate and stop near the COS cell aggregate recombinantly expressing versican V1. No such effect is observed in the control experiment with a $\mathrm{COS}$ cell aggregate transfected with the empty vector. Neurofilaments (red) and versican (green) are visualized by double immunofluorescence staining. Hoechst nuclear stain (blue) reveals the cellular localizations in the control. Fluorescence profiles averaged over a bandwidth of $200 \mu \mathrm{m}$ reveal the decline of neurite density (red line in $\boldsymbol{B}$ ) already $0.5 \mathrm{~mm}$ away from the versican-expressing (green line) $\operatorname{COS}$ cells in relation to the profile of a nearby control sector, in which neurites pass by the aggregate unhindered (gray line). Profiles of neurites and $C O S$ aggregates are virtually non-overlapping contrasting the control experiment ( $\boldsymbol{A}$; Hoechst, blue line; neurites, red line). Scale bar, $400 \mu \mathrm{m}$.

larger quantities of intact V0 and V1 isoforms (Dutt et al., 2006) has enabled us to study the inhibitory potential of versicans in peripheral axon growth in vitro and in vivo. In every assay of our present study, versican V0/V1 proved to override the axon growth promotion of extracellular matrix components such as laminin-1 and collagen-I. Most of this inhibitory potential appears to reside in the versican core protein structure, because complete removal of the chondroitin sulfate chains cannot neutralize this function. Nevertheless, the glycosaminoglycans and mucin-type $O$-glycans are certainly required for the structural integrity, which might explain the partial reduction of the inhibitory capacity of versicans after chondroitinase digestion.

The axonal response induced during encounter of versican V0/V1-containing areas is highly concentration dependent and ranges in our functional experiments from rapid retraction and deflection to defasciculation and growth arrest. These latter forms of attenuated versican inhibition are frequently observed in the collagen gel assays in vitro and in the injected hindlimbs in vivo. Compared with their endogenous counterparts, the ectopically positioned versicans V0/V1 are usually limited in quantity. Moreover, they are in vivo confronted with emerging proteolytic processes typically clearing the proteoglycans from future nerve pathways. By repeating the injections in regular intervals, we could at least partly circumvent this problem as illustrated by the clear inhibitory effects of versican observed in our in ovo study.

Interestingly, a similar concentration dependency of versican seems to control axonal behavior in the developing optic tectum of the chicken CNS (Yamagata et al., 1995). Here graded levels of versicans $\mathrm{V} 0 / \mathrm{V} 1$ are involved in the pathway restriction of retinal axons and in the regulation of lamina-specific arborization and presynaptic maturation.

Whether versican V0 and V1 act alone or in concert with other factors in the different boundary tissues is currently not known. However, concepts of direct functional links between these proteoglycans and semaphorins (Kantor et al., 2004; Huber et al., 2005) and/or ephrins (Wang and Anderson, 1997) in certain selective axonal barriers seem highly realistic and thus should be included in future strategies to explore the guidance processes in the developing nervous system.

\section{References}

Bandtlow CE, Zimmermann DR (2000) Proteoglycans in the developing brain - new conceptual insights for old proteins. Physiol Rev 80:1267-1290.

Davies JA, Cook GM, Stern CD, Keynes RJ (1990) Isolation from chick somites of a glycoprotein fraction that causes collapse of dorsal root ganglion growth cones. Neuron 4:11-20.

Domowicz M, Li H, Hennig A, Henry J, Vertel BM, Schwartz NB (1995) The biochemically and immunologically distinct CSPG of notochord is a product of the aggrecan gene. Dev Biol 171:655-664.

Dours-Zimmermann MT, Maurer K, Rauch U, Stoffel W, Fässler R, Zimmermann DR (2009) Versican V2 assembles the extracellular matrix surrounding the nodes of ranvier in the CNS. J Neurosci 29:7731-7742.

Dutt S, Kléber M, Matasci M, Sommer L, Zimmermann DR (2006) Versican V0 and V1 guide migratory neural crest cells. J Biol Chem 281:12123-12131.

Eberhart J, Swartz ME, Koblar SA, Pasquale EB, Krull CE (2002) EphA4 constitutes a population-specific guidance cue for motor neurons. Dev Biol 247:89-101.

Hamburger V, Hamilton HL (1951) A series of normal stages in the development of the chick embryo. J Morphol 88:49-92.

Hanson MG, Milner LD, Landmesser LT (2008) Spontaneous rhythmic activity in early chick spinal cord influences distinct motor axon pathfinding decisions. Brain Res Rev 57:77-85.

Helmbacher F, Schneider-Maunoury S, Topilko P, Tiret L, Charnay P (2000) Targeting of the EphA4 tyrosine kinase receptor affects dorsal/ventral pathfinding of limb motor axons. Development 127:3313-3324.

Huber AB, Kania A, Tran TS, Gu C, De Marco Garcia N, Lieberam I, Johnson D, Jessell TM, Ginty DD, Kolodkin AL (2005) Distinct roles for secreted semaphorin signaling in spinal motor axon guidance. Neuron 48:949964.

Kantor DB, Chivatakarn O, Peer KL, Oster SF, Inatani M, Hansen MJ, Flanagan JG, Yamaguchi Y, Sretavan DW, Giger RJ, Kolodkin AL (2004) Semaphorin $5 \mathrm{~A}$ is a bifunctional axon guidance cue regulated by heparan and chondroitin sulfate proteoglycans. Neuron 44:961-975.

Kennedy TE, Serafini T, de la Torre JR, Tessier-Lavigne M (1994) Netrins are diffusible chemotropic factors for commissural axons in the embryonic spinal cord. Cell 78:425-435.

Kramer ER, Knott L, Su F, Dessaud E, Krull CE, Helmbacher F, Klein R (2006) Cooperation between GDNF/Ret and ephrinA/EphA4 signals for motor-axon pathway selection in the limb. Neuron 50:35-47.

Landmesser LT (2001) The acquisition of motoneuron subtype identity and motor circuit formation. Int J Dev Neurosci 19:175-182.

Landolt RM, Vaughan L, Winterhalter KH, Zimmermann DR (1995) Versican is selectively expressed in embryonic tissues that act as barriers to neural crest cell migration and axon outgrowth. Development 121:2303-2312.

Lennon DP, Carrino DA, Baber MA, Caplan AI (1991) Generation of a monoclonal antibody against avian small dermatan sulfate proteoglycan: immunolocalization and tissue distribution of PG-II (decorin) in embryonic tissues. Matrix 11:412-427.

Lumsden AG, Davies AM (1983) Earliest sensory nerve fibres are guided to peripheral targets by attractants other than nerve growth factor. Nature 306:786-788.

Luria V, Krawchuk D, Jessell TM, Laufer E, Kania A (2008) Specification of motor axon trajectory by ephrin-B:EphB signaling: symmetrical control of axonal patterning in the developing limb. Neuron 60:1039-1053.

McCulloch DR, Nelson CM, Dixon LJ, Silver DL, Wylie JD, Lindner V, Sasaki T, Cooley MA, Argraves WS, Apte SS (2009) ADAMTS metallopro- 

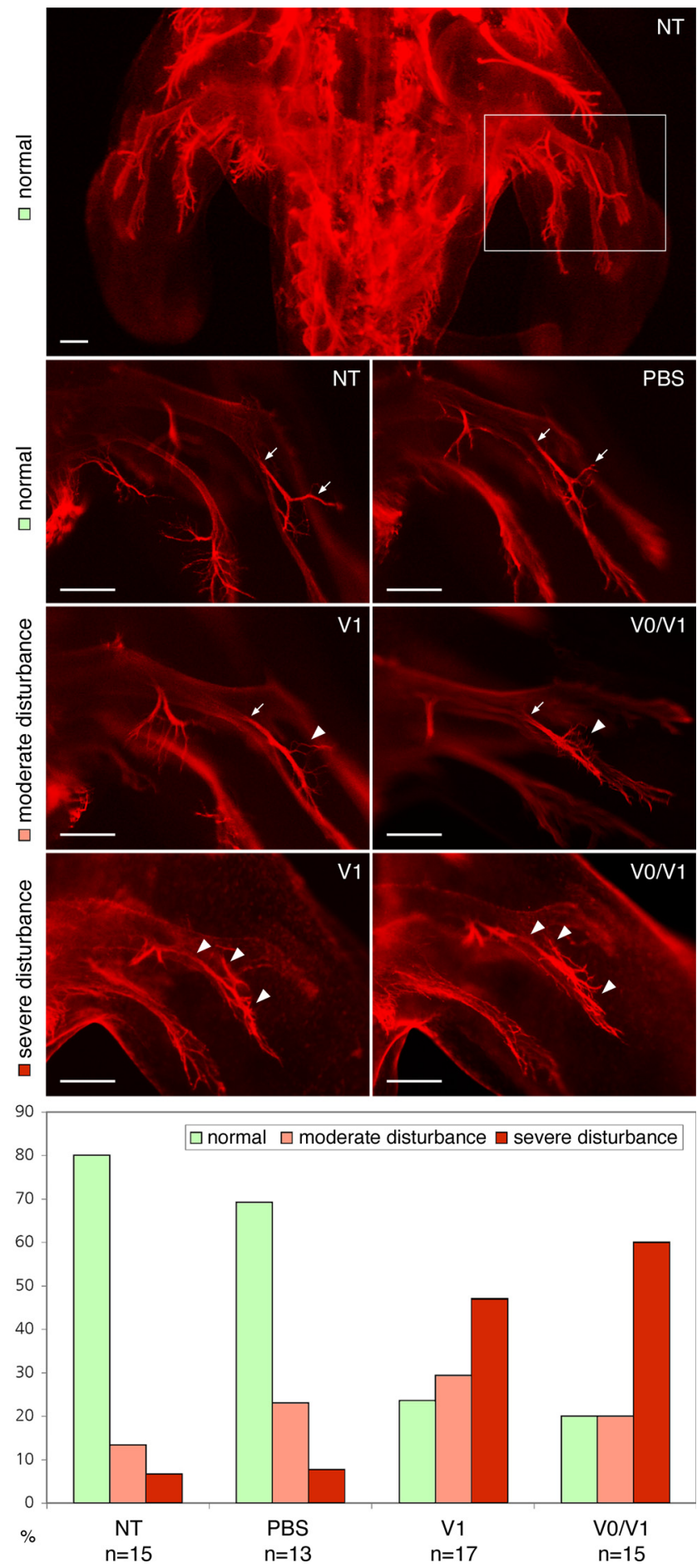

Figure 9. Consequences of ectopic deposition of versicans in developing chick hindlimb in ovo. Whole-mount immunofluorescence stainings of neurofilaments in $\mathrm{HH} 25$ embryos injected beforehand with PBS, versican V0/N1, or versican V1 preparations into the hindlimb are compared with nontreated controls (NT). The ectopic deposition of versican V0/N1 and V1 interferes with the normal growth, fasciculation, and branching of secondary nerve fibers emerging from dorsal trunk of the sciatic plexus. Normal branch points areindicated with arrows and aberrations with arrowheads. Scale bars, $200 \mu \mathrm{m}$. The proportions of normal, moderately, and severely disturbed growth patterns were recorded in a blind study revealing the clear effect of the versican injections. teases generate active versican fragments that regulate interdigital web regression. Dev Cell 17:687-698.

Mjaatvedt CH, Yamamura H, Capehart AA, Turner D, Markwald RR (1998) The cspg2 gene, disrupted in the $h d f$ mutant, is required for right cardiac chamber and endocardial cushion formation. Dev Biol 202:56-66.

Oakley RA, Tosney KW (1991) Peanut agglutinin and chondroitin-6-sulfate are molecular markers for tissues that act as barriers to axon advance in the avian embryo. Dev Biol 147:187-206.

Oakley RA, Lasky CJ, Erickson CA, Tosney KW (1994) Glycoconjugates mark a transient barrier to neural crest migration in the chicken embryo. Development 120:103-114.

Oettinger HF, Thal G, Sasse J, Holtzer H, Pacifici M (1985) Immunological analysis of chick notochord and cartilage matrix development with antisera to cartilage matrix macromolecules. Dev Biol 109:63-71.

Perris R, Johansson S (1990) Inhibition of neural crest cell migration by aggregating chondroitin sulfate proteoglycans is mediated by their hyaluronan-binding region. Dev Biol 137:1-12.

Ruegg MA, Stoeckli ET, Kuhn TB, Heller M, Zuellig R, Sonderegger P (1989) Purification of axonin-1, a protein that is secreted from axons during neurogenesis. EMBO J 8:55-63.

Schmalfeldt M, Dours-Zimmermann MT, Winterhalter KH, Zimmermann DR (1998) Versican V2 is a major extracellular matrix component of the mature bovine brain. J Biol Chem 273:15758-15764.

Schmalfeldt M, Bandtlow CE, Dours-Zimmermann MT, Winterhalter KH, Zimmermann DR (2000) Brain derived versican V2 is a potent inhibitor of axonal growth. J Cell Sci 113:807-816.

Shinomura T, Kimata K, Oike Y, Maeda N, Yano S, Suzuki S (1984) Appearance of distinct types of proteoglycan in a well defined temporal and spatial pattern during early cartilage formation in the chick limb. Dev Biol 103:211-220.

Snow DM, Lemmon V, Carrino DA, Caplan AI, Silver J (1990) Sulfated proteoglycans on astroglial barriers inhibit neurite outgrowth in vitro. Exp Neurol 109:111-130.

Stoeckli ET, Landmesser LT (1995) Axonin-1, Nr-CAM, and Ng-CAM play different roles in the in vivo guidance of chick commissural neurons. Neuron 14:1165-1179.

Tosney KW (1991) Cells and cell-interactions that guide motor axons in the developing chick embryo. Bioessays 13:17-23.

Tosney KW, Landmesser LT (1985) Development of the major pathways for neurite outgrowth in the chick hindlimb. Dev Biol 109:193-214.

Vielmetter J, Stolze B, Bonhoeffer F, Stuermer CA (1990) In-vitro assay to test differential substrate affinities of growing axons and migratory cells. Exp Brain Res 81:283-287.

Wang G, Scott SA (2000) The "waiting period" of sensory and motor axons in early chick hindlimb: its role in axon pathfinding and neuronal maturation. J Neurosci 20:5358-5366.

Wang HU, Anderson DJ (1997) Eph family transmembrane ligands can mediate repulsive guidance of trunk neural crest migration and motor axon outgrowth. Neuron 18:383-396.

Yamagata M, Saga S, Kato M, Bernfield M, Kimata K (1993) Selective distributions of proteoglycans and their ligands in pericellular matrix of cultured fibroblasts. Implications for their roles in cell-substratum adhesion. J Cell Sci 106:55-65.

Yamagata M, Herman JP, Sanes JR (1995) Lamina-specific expression of adhesion molecules in developing chick optic tectum. J Neurosci $15: 4556-4571$

Zimmermann DR, Dours-Zimmermann MT (2008) Extracellular matrix of the central nervous system: from neglect to challenge. Histochem Cell Biol 130:635-653.

Zimmermann DR, Ruoslahti E (1989) Multiple domains of the large fibroblast proteoglycan, versican. EMBO J 8:2975-2981.

Zimmermann DR, Dours-Zimmermann MT, Schubert M, BrucknerTuderman L (1994) Versican is expressed in the proliferating zone in the epidermis and in association with the elastic network of the dermis. J Cell Biol 124:817-825. 